\title{
CONTRIBUIÇÕES DA FORMAÇÃO TÉCNICA DO AGENTE COMUNITÁRIO DE SAÚDE PARA O DESENVOLVIMENTO DO TRABALHO DA EQUIPE SAÚDE DA FAMÍLIA
}

\author{
CONTRIBUTION TO THE WORK OF THE FAMILY HEALTH TEAM IN THE TECHNICAL TRAINING OF THE \\ HEALTH COMMUNITY AGENT
}

\section{CONTRIBUCIÓN CON EL TRABAJO DEL EQUIPO SALUD FAMILIAR EN LA FORMACIÓN TÉCNICA DEL AGENTE COMUNITARIO DE SALUD}

\author{
Vera Joana Bornstein ${ }^{1}$ \\ Helena Maria Scherlowski Leal David ${ }^{2}$
}

Resumo Este artigo aborda os resultados de pesquisa realizada entre 2008 e 2011 no âmbito da Escola Politécnica de Saúde Joaquim Venâncio, cujo objeto foi a formação técnica do agente comunitário de saúde (ACS). O eixo central de análise foram as mudanças produzidas no processo de trabalho decorrentes da reorientação do modelo de atenção à saúde pretendida com a implantação da Estratégia Saúde da Família. Participaram da pesquisa 32 ACSs alunos do curso, oito profissionais das suas equipes e dois ACSs da diretoria do Sindicato de Agentes Comunitários de Saúde do Rio de Janeiro que não eram alunos do curso. De maneira geral, os entrevistados questionaram as conquistas pretendidas com a mudança no modelo de atenção. Quanto à contribuição da formação técnica para a atuação dos ACSs, existe uma contradição clara entre a percepção deles e a perspectiva de médicos e enfermeiros. Enquanto esses últimos perceberam poucas mudanças ocorridas na atuação dos ACSs em decorrência do curso realizado, os agentes foram unânimes em apontar mudanças em relação ao trabalho e à sua própria vida. A tensão na relação entre ACSs e demais profissionais da equipe esteve presente nos resultados da pesquisa e indica uma necessidade de aprofundamento dessa relação.

Palavras-chave formação profissional; agente comunitário de saúde; saúde da família.
Abstract This article presents the findings of a research project undertaken at Escola Politécnica de Saúde Joaquim Venâncio (EPSJV) (Joaquim Venâncio Polytechnic School of Health/Oswaldo Cruz Foundation), which analyzed the Community Health Agents (CHA) technical course between 2008 and 2011. The research was developed from the point of view of CHAs, and also from the point of view of the other family health team members. The research used as guideline the modifications produced in the work process taking into account the changes introduced in the health care model that had been intended with the implementation of the Family Health Strategy. Thirty-two CHAs students of the course, eight members of their teams and two CHA members of the head office of SINDACS-RJ (Health Community Agents Trade Union - Rio de Janeiro) which were not students took part in the research. In general terms, the achievements that had been intended with the changes in the health care model were disputed by interviewees. As for the contribution the technical courses had on CHAs' performance, there is a clear contradiction between the perceptions of CHAs and that of physicians and nurses. While the latter observed few changes after CHAs took the technical course, the former unanimously pointed out changes not only in their work but also in their lives. The tension underlying the relations between the CHAs and the other team members appeared in the research results. Hence, there is a need to investigate into this matter. Keywords professional education; community health agent; family health. 


\section{Introdução}

O presente artigo aborda os resultados de pesquisa realizada no âmbito da Escola Politécnica de Saúde Joaquim Venâncio (EPSJV), cujo objeto foi a formação técnica do agente comunitário de saúde (ACS). O primeiro enfoque, que tratou da perspectiva dos ACSs, foi realizado por meio de um estudo de caso com os agentes de saúde que iniciaram sua formação técnica em 2008 na EPSJV. Seu objetivo foi analisar as relações entre o processo de formação dos ACSs e seu papel mediador na perspectiva de reorientação do modelo de atenção à saúde pretendido com a implantação da Estratégia Saúde da Família (ESF). O segundo enfoque, realizado entre 2010 e 2011, buscou aprofundar a análise sobre as contribuições da formação técnica do ACS, incluindo a perspectiva dos demais profissionais e de membros da diretoria do Sindicato de Agentes Comunitários de Saúde do Rio de Janeiro (Sindacs-RJ).

A criação do Programa de Agentes Comunitários de Saúde (Pacs) e, posteriormente, da Estratégia Saúde da Família procurou recuperar diferentes experiências realizadas no Brasil, destacando-se a experiência de agentes comunitários do Ceará, onde foi criada uma 'frente de trabalho' em uma conjuntura de seca. Em sua maioria, os agentes de saúde eram mulheres, que passaram a realizar ações básicas de saúde em 118 municípios do sertão cearense (Souza, 2002).

A partir de 1997, o Pacs e a ESF passaram a ser prioridades do Plano de Metas do Ministério da Saúde. No documento Politica Nacional de Atenção Básica, a ESF é citada como estratégia prioritária para a reorganização da atenção básica no Brasil, substituindo o modelo tradicional de assistência, voltado para a cura de doenças e 'hospitalocêntrico', por outro, cujas principais características são o enfoque sobre a família com base em seu ambiente físico e social como unidade de ação; a adscrição de clientela mediante a definição de território de abrangência da equipe; a estruturação de equipe multiprofissional; a ação preventiva em saúde; a detecção de necessidades da população em vez da ênfase na demanda espontânea; e a atuação intersetorial com vistas à promoção da saúde (Brasil, 2006).

Tanto o Pacs como a ESF têm em comum a figura do ACS como elemento inovador no quadro funcional. Sobre ele recaem expectativas de mediação e facilitação do trabalho de atenção básica em saúde, daí a importância de aprofundar estudos sobre seu processo de trabalho e formação, numa perspectiva de mudança de modelo. Esses trabalhadores representam, hoje em dia, aproximadamente 248 mil trabalhadores na atenção básica em saúde (Brasil, 2011).

No âmbito das práticas cotidianas dos serviços, fazem-se presentes disputas de interesses variados, mais ou menos explícitos. Com frequência, o ACS se encontra no meio de uma disputa pela hegemonia do controle sobre seu processo de trabalho, envolvendo os interesses políticos dos ges- 
tores, a visão técnica dos enfermeiros responsáveis e as necessidades das pessoas da comunidade.

Carmem Teixeira (2006, p. 29) chama atenção para a complexidade de um processo de mudança do modelo de atenção à saúde que exige um conjunto heterogêneo de iniciativas 'macro' sistêmicas, tais como formulação e implantação de políticas que criem condições para as mudanças no nível 'micro' - nível do processo de trabalho em saúde.

Ainda que conscientes dessa complexidade, buscaremos aqui problematizar as mudanças no processo de trabalho do agente comunitário relacionadas com a sua formação profissional.

\section{A formação profissional do ACS}

A concepção político-pedagógica de formação profissional que fundamenta este artigo é a da politecnia, que, de acordo com Pereira e Ramos, "possui como eixo central 'o trabalho como princípio educativo', articulado com a pesquisa como princípio educativo, e a elegia da arte e do pensamento filosófico como inerentes à integração dos conhecimentos científicos, e destes com a vida cotidiana" (2006, p. 57).

Na concepção politécnica, a formação profissional é entendida como a articulação da formação geral com os conhecimentos específicos e da teoria com a prática; e como o processo de trabalho em unidade indissolúvel entre os aspectos manuais e intelectuais. A superação dessas divisões exige transformações sociais no sentido de uma sociedade onde os trabalhadores possam se apropriar do saber de uma forma global, o que por sua vez exige a transformação das próprias relações sociais de produção.

A essa concepção de formação contrapõe-se a perspectiva da formação de base tecnicista e utilitarista, que confere um sentido meramente instrumental ao processo educativo, e que, embora venha sendo alvo de críticas por parte de educadores, tende a predominar numa economia de mercado.

Morosini, Corbo e Guimarães (2007) buscam reconstituir a história recente de profissionalização dos ACSs e abordam diferentes estratégias de formação profissional desenvolvidas no âmbito da Estratégia Saúde da Família. Mencionam as capacitações em serviço predominantes até o momento anterior à proposta constante no Referencial Curricular para o Curso Técnico de Agente Comunitário de Saúde (Ctacs). As principais características dessas capacitações em serviço são as de ser uma formação inicial de educação profissional, não regulamentada, sem pré-requisitos além de não conferir habilitação. As autoras comentam que esse tipo de formação "fortalece a desvalorização social desse trabalhador, sustenta sua baixa remuneração e contrapõe-se à pauta política por uma melhor qualificação dos 
trabalhadores de saúde, de uma maneira geral" (Morosini, Corbo e Guimarães, 2007, p. 267).

No segundo semestre de 2004, o Ministério da Saúde, em conjunto com o Ministério da Educação, publicou o Referencial curricular para curso técnico de agente comunitário de saúde: área profissional saúde (Brasil, 2004). Nessa proposta, é construído um itinerário formativo visando à profissionalização técnica e está presente a preocupação com a elevação concomitante da escolaridade dos ACSs. Os cursos de formação técnica desses profissionais ficam a cargo da Rede de Escolas Técnicas do Sistema Único de Saúde (RET-SUS). Morosini, Corbo e Guimarães (2007) referem-se à existência de contradição entre o texto do Referencial Curricular e o texto da lei n. 11.350, aprovada em 2006. Enquanto o primeiro estabelece um itinerário formativo de 1.200 horas, distribuídas em três etapas que incluem a prática profissional, a mencionada lei apresenta como requisito para o exercício da função de ACS a conclusão do ensino fundamental e de um curso introdutório de formação inicial e continuada.

Até o momento, tem sido difícil garantir a formação técnica completa em âmbito nacional. Uma das argumentações contrárias à realização do curso técnico em suas três etapas se fundamenta na Lei de Responsabilidade Fiscal, 3 dado que esses trabalhadores, ao se tornarem técnicos, poderiam reivindicar aumento dos salários. Na maioria dos estados, parte dos ACSs realizou apenas a primeira etapa desse curso técnico. No momento do término da pesquisa, algumas das exceções eram os estados do Tocantins e do Acre, onde o curso foi finalizado em suas três etapas, e uma turma da EPSJV, que concluiu as três etapas em julho de 2011.

Esse trabalhador foi inserido muito recentemente na história das profissões da saúde, e, portanto, o núcleo teórico e pedagógico que informa os seus processos formativos constitui espaço de disputas diversas. Nele se incluem tanto posicionamentos que entendem o ACS apenas como trabalhador voluntário e não profissionalizado - configuração de alguns países latino-americanos, como México e Peru - até a proposta brasileira. Essa última conseguiu fazer-se presente por meio de bases jurídico-normativas e políticas com as quais se busca oportunizar o processo de ampliação da escolaridade e a organização profissional, a inclusão social e a capacidade de os ACSs se constituírem em mão de obra qualificada para a atenção à saúde da comunidade, no seu nível de competência.

\section{Aspectos metodológicos}

A metodologia utilizada neste estudo se baseou na abordagem histórico-dialética. O aspecto mediador e relacional do trabalho do ACS se dá em con- 
dições que não são bem conhecidas, e as relações que o ACS estabelece com os serviços, gestores e a comunidade são singulares. Estimular a explicitação coletiva dessas relações e processos sociais, do ponto de vista da pesquisa, favorece a construção de um processo dialético que reconhece o trabalho como práxis e permite ampliar a compreensão sobre como, nas ações cotidianas, se constroem e relacionam as redes de conhecimentos e as mudanças da prática assistencial. O conceito de diálogo em Freire (1987) também expressa a opção da relação entre pesquisadores e pesquisados buscada neste estudo: a palavra viva como diálogo existencial: reconhecer o outro, e a si próprio, em si e no outro.

Nessa perspectiva, procurou-se evidenciar e analisar, com base no material obtido nas oficinas e entrevistas, as contradições, as diferenças, os contrastes, o dissenso e a ruptura de sentido nesse contexto dos sujeitos/grupos. Minayo (1999) destaca a importância da hermenêutica e da dialética como momentos necessários da produção de racionalidades em relação aos processos sociais. Nesse sentido, as narrativas, obtidas por meio de entrevistas individuais e na modalidade grupo focal, após serem transcritas, constituem o texto que permitiu a aproximação ao universo simbólico dos sujeitos participantes, e às descrições objetivas sobre as contradições que permeiam o trabalho dos ACSs.

Os sujeitos do estudo foram 32 ACSs alunos do Ctacs realizado na EPSJV, oito profissionais das equipes de Saúde de Família e dois ACSs da diretoria do Sindacs-RJ que não eram alunos do Ctacs. A coleta de dados foi realizada em três momentos distintos, durante o desenvolvimento do curso de formação técnica concluído em julho de 2011.

Para aproximação à perspectiva dos agentes comunitários, foram realizados três grupos focais com os 32 alunos do Ctacs realizado na EPSJV. Os grupos focais se fundamentaram na ideia de que, por meio de abordagens participativas, pode-se construir um processo de descrição e problematização do trabalho cotidiano. Os temas abordados foram: contexto em que se realiza o trabalho da equipe, incluindo o modelo de atenção; processo de formação vivenciado pelos ACSs; seu cotidiano de trabalho; educação em saúde realizada recentemente; novas práticas de trabalho após o início do curso técnico; mudanças observadas na qualidade do trabalho; e valorização da formação pela equipe. As falas retiradas das transcrições dos grupos focais e de entrevistas realizadas com esses profissionais são sinalizadas com a sigla ACS.

Foi realizada ainda uma observação não estruturada, durante o acompanhamento do Ctacs, com o objetivo de complementar, exemplificar e checar o material colhido por meio de entrevistas e grupos focais. As situações e comportamentos observados foram relatados num diário de campo da forma como ocorreram, visando descrever e compreender o que estava ocorrendo. 
Ao final do curso, foi aplicado um questionário aberto e anônimo, com o objetivo de conhecer a percepção dos alunos sobre a influência do curso em suas vidas e em seu trabalho. Esse questionário foi preenchido por 19 dos 20 alunos que finalizaram o curso. As falas retiradas dos questionários são sinalizadas com a sigla Qacs.

As narrativas trazendo a perspectiva dos demais profissionais da equipe e de representantes do sindicato foram obtidas por entrevistas com quatro médicos e quatro enfermeiros, além de dois diretores do Sindacs-RJ. Essas entrevistas abordaram: sua percepção do ACS como profissional de saúde e contribuições para sua própria prática profissional; a participação dos profissionais na formação dos ACS; sugestões para a formação; e percepção sobre a formação realizada. Suas falas são identificadas com a letra M para médicos e E para enfermeiros.

As entrevistas com os diretores do Sindacs-RJ abordaram a importância do trabalho do ACS e de sua formação profissional; o processo de trabalho; e a relação com a equipe. Suas falas são também identificadas com a sigla ACS, no intuito de preservar suas identidades.

Ambas as dimensões abordadas foram aprovadas pelo Comitê de Ética em Pesquisa/EPSJV/Fiocruz.

\section{Resultados e discussão}

Na organização e sistematização dos dados, duas dimensões emergiram como eixos norteadores da análise: a primeira diz respeito ao processo de trabalho do ACS e sua relação com o trabalho da equipe; a segunda enfoca as mudanças percebidas durante a sua formação profissional. Em ambos os eixos, coloca-se em diálogo a perspectiva dos agentes comunitários e a dos demais profissionais da equipe. No eixo processo de trabalho, as categorias analíticas são: integralidade/fragmentação; demanda espontânea/demanda programada; continuidade e vínculo; e trabalho educativo.

\section{Integralidade/fragmentação}

Em oposição à fragmentação na atenção, toma-se aqui o sentido de integralidade como o entendimento da interação de diferentes dimensões da vida que atuam sobre o processo saúde/doença, bem como a necessidade de integração das ações e dos serviços de saúde (Mattos, 2001). Nesse sentido, a Estratégia Saúde da Família constituiria ambiente favorável para ações baseadas na integralidade da atenção, ao possibilitar o entendimento do contexto de vida da população e a base a partir da qual se deve organizar a rede de serviços de saúde. 
A abordagem integral feita pelos agentes de saúde está presente em vários de seus depoimentos. $\mathrm{O}$ fato de entrar na casa da família lhes permite observar situações que nem sempre são abordadas nas consultas, verificando a relação entre seus moradores e suas condições de vida.

Uma coisa que eu reparei depois que eu ingressei no trabalho de ACS é que onde se tem uma moradia com um espaço físico muito pequeno e uma família muito grande, geralmente, você tem mais violência na família, mais casos de doenças e com certeza menos qualidade de vida (ACS).

De maneira geral, os médicos e enfermeiros entrevistados reconhecem que o agente comunitário é um profissional de saúde cuja especificidade é o fato de ser um morador da sua área de trabalho e de realizar grande parte do seu trabalho no território. Essas características lhe possibilitam facilitar a relação dos médicos e enfermeiros com a população, e identificar os fatores de risco que necessitam da atenção da equipe.

Eu brinco que eles são os meus olhos. Os agentes atuam para estar trazendo os agravos, fazendo promoção [da saúde]. Eu tenho um turno maior de consultório, um turno menor para campo; então, como eles estão sempre na área, eles estão mais atualizados de doenças que a gente (M1).

A percepção das condições e da situação em que vivem os moradores da área facilita a compreensão no que se refere às suas reações e à criação de vínculo com os moradores.

Não concordo em dizer que os moradores tenham falta de educação. Até mesmo porque são pessoas muito sofridas, eles não têm tempo para ter paciência com mais nada. Eu considero todos eles que moram aí dentro uns heróis. Porque é muito sofrimento. Sofrimento por causa da violência com que eles convivem aí, pelas dificuldades, a falta de tudo, ninguém dá valor pra eles... (ACS).

Em relação à contribuição dos ACSs para o atendimento feito por enfermeiros e médicos, existe o entendimento de sua contribuição tanto na compreensão da própria realidade quanto no entrosamento com a população.

Eu acho que é a questão da linguagem, de se compreender a realidade por você ser parte dela; porque às vezes a gente vem de uma realidade diferente, então é difícil entender por que uma mãe está trancando a menina de 14 anos dentro de casa, mas o agente comunitário ele ajuda a gente a percebe a questão da dinâmica social mesmo. Como é que eles se relacionam entre si, com a escola, com o baile, com a rua (M2). 
O potencial da integralidade contrasta com a visão fragmentada dos profissionais que permanecem dentro da unidade de saúde principalmente e que tendem a reproduzir a lógica de comunicação e vínculo aprendida na sua formação profissional, lógica que, segundo Vasconcelos (1999), tende a delimitar de forma assimétrica a relação entre serviços e população, interferindo na possibilidade de uma abordagem com base na integralidade.

Eu estou dentro da sala, eu vejo um lado [do problema] quando eu estou fechada aqui. Já o agente de saúde me traz o contexto: “Olha, aquela senhora é aquela que a gente visitou e que morreu fulano...". Ele me traz o contexto familiar ou o do próprio momento pelo qual eles estão passando ou de alguma experiência anterior e me ajuda muito (M4).

Por outro lado, os ACSs comentam que a própria população tem um entendimento do papel do médico como um profissional que vai dar consulta e fornecer remédio.

A proposta do PSF [Programa Saúde da Família, posteriormente chamado Estratégia Saúde da Família] é o acompanhamento, é a prevenção, e as pessoas não estão acostumadas com essa ideia de prevenção. Elas estão acostumadas com a ideia de consulta médica, de ser atendido. E o Programa Saúde da Família é um trabalho de acompanhamento (ACS).

\section{Demanda espontânea/demanda programada}

Uma das características das unidades de saúde tradicionais é a priorização da intervenção sobre as doenças, e, nesse sentido, a organização do serviço ocorre, sobretudo, considerando a demanda espontânea. Entre as mudanças propostas pela ESF, está a organização dos serviços e das práticas de saúde com ênfase na demanda programada, de acordo com as necessidades locais e orientações programáticas do serviço. Na busca de produzir um impacto positivo sobre a saúde da população, procurou-se organizar o serviço a partir da epidemiologia, no sentido de detectar as necessidades de saúde da população.

Merhy e Franco (2003) sustentam que o PSF baseia suas propostas nos conhecimentos relacionados à epidemiologia e à vigilância à saúde, o que não é suficiente em muitas situações quando o conjunto da prática clínica for essencial para atender às necessidades de assistência da população.

O conflito existente entre a proposta da ESF de priorizar a demanda programada e as expectativas da população de ver suas necessidades imediatas (demanda espontânea) atendidas é mencionado pelos ACSs: 
O Programa Saúde da Família tem um olhar no sentido da promoção da saúde, é acompanhamento, é ver se a pessoa tem que renovar receita, ver se o tipo de remédio acabou; só que a comunidade, ela não está interessada nisso. Por quê? Porque o olhar da comunidade é só consulta, consulta, consulta (ACS).

Segundo a informação dos ACSs, a priorização no atendimento da equipe é dada para gestantes, crianças, hipertensos, diabéticos, portadores de tuberculose e hanseníase. Essas prioridades correspondem aos programas orientados pelo Ministério da Saúde, cujas informações servem de parâmetro para a avaliação do trabalho.

Apesar de os ACSs participarem, em geral, da triagem feita diariamente para priorizar o atendimento da demanda espontânea, muitos deles consideram não ter informações suficientes para realizar essa tarefa.

\section{Continuidade e vínculo}

A característica de territorialidade consiste no estabelecimento de uma área e de um determinado número de famílias que deve ser acompanhado por cada equipe. Espera-se da equipe de saúde da família a continuidade na prestação de serviços de saúde à população e a criação de um vínculo entre equipe e população.

A continuidade e o estabelecimento de vínculo entre a equipe e a população são abordados pelos agentes de saúde como uma forma de detectar situações antes mesmo que elas cheguem ao serviço e de atender com presteza às necessidades dos moradores.

Eu tenho uma gestante agora que eu tentei acompanhar desde o início. Ela me disse que ia tirar o neném e tentou até os seis meses tirar. Foi começar o pré-natal agora. Eu logo peguei o cartão dela, levei para a médica. A médica pediu os exames e ela já está agendada para uma consulta. Eu acredito que possa até ter paralisação [do serviço] no dia 5, mas, se houver, eu vou tentar falar com ela [a médica] e mudar essa data para [uma data] mais próxima (ACS).

A narrativa evidencia que os agentes exercem uma prática que se desvincula do trabalho normatizado e prescrito, e buscam tecer, criativamente, uma prática com base em valores solidários e de cuidado com as pessoas e famílias sob sua responsabilidade. Também a legitimidade do agente na população de sua comunidade se fortalece nesse processo.

O acompanhamento da população é considerado um diferencial em relação ao serviço prestado pelo centro de saúde, e possibilita a continuidade no tratamento e o desenvolvimento de um trabalho educativo. 
No centro de saúde, você está doente naquele dia, vamos passar um remédio e você vai voltar para casa. Se você não voltar, você não vai ter um acompanhamento. Com a entrada do PSF, tem uma pessoa que vai à casa [do doente] para saber como é que ele está tomando esse medicamento, se ele está tomando do jeito certo, falar da alimentação, dieta, exercício físico... (ACS).

Em relação ao vínculo, os ACSs afirmaram que nem todos os profissionais têm o mesmo compromisso, e o fato de alguns permanecerem sobretudo dentro da unidade de saúde pode propiciar o seu distanciamento da população. Por outra parte, o conhecimento dos ACSs em relação à população possibilita uma maior cobrança da própria população, assim como permite distinguir situações que necessitam de atenção diferenciada.

A gente conhece quem trabalha, quem não... Se o morador só tem livre a segunda-feira, a gente procura na agenda uma segunda-feira em que se possa marcar a pessoa. E fala para ele: "Olha, na segunda-feira, que é o dia em que você pode vir, só tem essa data". E eles ficam satisfeitos: "Ah! Obrigado". Mesmo sendo um pouco longe, ele viu que você se esforçou para encaixá-lo (ACS).

A percepção do vínculo rompe com a lógica da atenção com base exclusivamente no processo patológico e avança para a produção de um processo de trabalho que recoloca o ACS como alguém que não apenas 'faz o que se manda', mas que também cria estratégias e modos de agir com base numa sabedoria prudente e solidária. Nesse sentido, pode-se afirmar que se estabelecem formas de trabalho que, em grande parte, dependem do jeito e do conhecimento do trabalhador para a sua produção, mas que, por não corresponderem unicamente à lógica predeterminada dos serviços, possuem pouca ou nenhuma visibilidade e importância.

\section{Trabalho educativo}

As diferentes formas de se conduzir o trabalho educativo refletem diferentes concepções do processo de produção do conhecimento e diferentes concepções políticas. Considera-se que o trabalho educativo realizado pelo agente de saúde pode ser de grande importância para a mudança do modelo de atenção, na medida em que fortaleça a autonomia da população e possibilite a expressão de suas necessidades, sua organização e a construção de um sistema de saúde humanizado. Nesta pesquisa, procurou-se diferenciar duas formas de condução do trabalho educativo: uma primeira, caracterizada por seu aspecto de convencimento da população por parte do profissional de saúde que se julga detentor de um saber; e outra, fundamentada no diálogo, no reconhecimento 
do saber do outro, na reflexão crítica sobre a realidade e no fortalecimento da autonomia e do trabalho coletivo (Bornstein e Stotz, 2008-2009).

O trabalho educativo em nível individual é considerado de grande importância pelo ACS, que destaca sua dimensão informativa e reconhece ser essa uma dimensão importante de seu trabalho.

O que mudou com a chegada do PSF na minha comunidade foi fundamentalmente a informação, que é o nosso trabalho! Antes havia pessoas que não sabiam que eram hipertensas, diabéticas, e quem sabia, não sabia como controlar. Hoje, os [hipertensos] severos principalmente sabem que têm de cozinhar o dia inteiro com uma tampinha de caneta de sal. Então, eu acho que o grande lance na mudança do PSF é a coisa da informação (ACS).

Em relação ao trabalho educativo coletivo, tanto os ACSs quanto os médicos e enfermeiros relatam que a maior parte dos trabalhos educativos está vinculada a programas de saúde ou a doenças. Foi mencionado o trabalho educativo para grupos de hipertensos e diabéticos, preventivo, planejamento familiar, puericultura, escabiose e idosos. Geralmente, os grupos são feitos na unidade de saúde, e grande parte dos ACSs mencionou não existir interesse da população neles, por causa da distância e da expectativa do atendimento médico. Entre os ACSs é comum a fala de que o trabalho educativo formal é conduzido pelos demais membros da equipe, e que eles se sentem excluídos desse processo.

O pessoal não gosta de grupo. Eles só vão se tiver alguma coisa. É “vai ter cesta básica"? (ACS).

A gente está presente, só que a gente não fala nada, a gente chama o povo, a gente reforça, vai às casas (ACS).

Quando eu comecei, no ano de 2000, nós começamos a fazer o grupo. Só que a gente fazia no posto de saúde. O que acontecia? O número de pessoas era mínimo. Aí nós começamos a procurar um espaço na comunidade, e conseguimos (ACS).

Por outra parte, uma das enfermeiras afirma que acharia importante que os ACSs participassem do planejamento e da condução dos grupos educativos e que, mesmo quando solicitados, parece haver uma acomodação dos ACSs em deixar esse trabalho para médicas/os e enfermeiras/os.

Um contraste no que diz respeito aos relatos feitos pela maioria dos ACSs é a atividade educativa relatada por dois dos ACSs participantes da pesquisa. Ambos organizaram atividades educativas feitas na comunidade e os temas não estavam diretamente vinculados a programas ou doenças. 
Nossos grupos de promoção são feitos pelos agentes comunitários. Não é feito pela enfermeira. Os grupos são sempre cheios, principalmente os grupos de adultos. No último grupo de mulheres a gente falou sobre a violência doméstica. A gente tem um curso de gestante que foi desenvolvido pelos agentes comunitários. Algumas enfermeiras de lá [da unidade de saúde] falaram que agente comunitário não pode fazer curso; aí tiramos o nome de curso e botamos como "grupo de gestante", que é desenvolvido no primeiro, segundo e terceiro trimestres de gestação (ACS).

Hoje eu tenho um chamado grupo dos homens, que é um grupo onde nós falamos sobre a saúde do homem. Na época, éramos três (ACS). Passamos pela nossa comunidade e observamos que, na parte da manhã e na parte da tarde, muitos senhores aposentados estavam na porta de botequins, e daí veio a ideia: por que a gente não cria um grupo de homens? (ACS).

De maneira geral, os agentes de saúde manifestaram que a equipe de saúde estava desenvolvendo poucas atividades educativas na comunidade. No entanto, foi mencionado o trabalho educativo feito durante as visitas domiciliares e o trabalho educativo não programado, feito pelo agente de saúde na comunidade como um espaço potencial desse tipo de trabalho.

É muito difícil convidar aquela comunidade, mas se tiver dez pessoas na pracinha, eu faço o trabalho educativo em qualquer lugar, até no botequim eu faço (ACS).

Esse é um indicativo da necessidade de valorizar os espaços informais, incluindo-os como possibilidade de trabalho.

O entendimento do trabalho educativo como convencimento está presente na fala de alguns ACSs, ainda que também exista a avaliação da falta de efetividade desse trabalho de convencimento.

Minha satisfação maior como agente de saúde é ver que a minha promoção atingiu o coração daquele paciente. Falar é uma coisa, mas ver que a pessoa ouviu e acatou é outra. E você vai ver que a tua promoção chegou a ele se ele estiver fazendo realmente aquilo que você passou para ele (ACS).

Falar eu falo, mas não depende só de mim. Não adianta só eu falar, falar, e nada acontecer (ACS).

Encontramos também uma abordagem mais dialógica do trabalho educativo, em que o ACS busca entender a realidade da população. Na fala a seguir, a agente de saúde menciona o trabalho educativo feito na comunidade de maneira informal, nos espaços frequentados por ela em seu dia a dia. 
Eu canso de debater com a nossa equipe que a gente quer fazer um grupo para falar, mas a gente nunca fez um grupo para ouvir o que eles têm para falar (ACS).

Eu tenho um grupo de pessoas que tem uma opção sexual meio aflorada, um pessoal que eu faço cabelo, e assim eu fico ouvindo sacanagem, brincando, e uma vez ou outra, eu falo: "Sabe que essa verruga assim pode [...] ser perigoso?" Vir aqui no posto eles não vão vir, porque ninguém quer acordar cedo, ter hora de chegar e não ter hora de sair (ACS).

Esses depoimentos indicam a coexistência de diferentes formas de condução do trabalho educativo entre a equipe de saúde da família.

\section{Formação técnica do ACS e mudanças percebidas durante a formação}

A importância do curso técnico é uma unanimidade entre os agentes de saúde que participaram da pesquisa, tanto para os alunos da EPSJV quanto para a diretoria do Sindacs-RJ, que lutou por sua realização.

Uma formação de qualidade vai te ajudar a resolver alguns entraves, assim, [para] você buscar soluções, buscar parcerias, buscar ampliar as opções, e também [para] entender melhor minhas limitações, até onde posso ir, entender o seu trabalho, porque é tão complexo o trabalho do agente comunitário que você às vezes vira um mecânico. Hoje em dia, eles pedem muitos números, nada é qualitativo é tudo quantitativo. Eu acho que o curso técnico dá mais uma visão de qualidade do seu trabalho (ACS).

O introdutório [curso inicial], eu acho que ele é necessário antes de pegar o agente comunitário e jogar ele lá, sem conhecimento de nada. O curso técnico é o complemento daquilo que ele começou a fazer. Eu não vejo um querendo apagar a existência do outro, não. O ACS tem de ser um técnico naquilo que ele faz (ACS).

Tanto nas entrevistas quanto no questionário aplicado ao final do curso todos os ACSs mencionaram mudanças positivas em seu processo de trabalho, percebidas no decorrer do curso. Referem-se à compreensão de um modelo de atenção mais humanizado e integral, e ao trabalho intersetorial.

Eu me senti mais qualificada para promover ações educativas, pois antes só o médico e o enfermeiro eram qualificados, e para ter um olhar ampliado - pois diferenciado eu já tinha -, ampliado no sentido de olhar o indivíduo como um todo, levando em consideração modo de vida, hábitos, aspectos culturais, sociais etc. (Qacs). 
No que se refere aos aprendizados relacionados com o processo de trabalho, os agentes de saúde destacam conhecimentos adquiridos em relação às políticas de saúde, ao planejamento, à informação e à educação em saúde.

Depois do técnico de ACS, principalmente do primeiro módulo, percebi a importância de se preencher a ficha A. Uma coisa que eu não preenchia antes era uma pergunta sobre de onde a pessoa tinha vindo. Eu vi porque aquilo era importante, porque era a história da pessoa, por onde ela já passou. Ela tinha uma história lá atrás... (ACS).

O que eu mais aproveitei foi a parte do relato, como relatar minha visita, quais situações são importantes para eu descrever (ACS).

Descobri que sou capaz de conduzir um grupo (Qacs).

Consideram que as mudanças também se refletiram nas suas relações com a equipe.

O curso vem mesmo amadurecendo cada um de nós. De repente, a gente só convocava e ia buscar [o morador]. O curso faz que a gente se coloque diferente, não só como a que busca, mas como a que participa (ACS).

Eu me senti mais segura para desenvolver o meu trabalho, aprendi a me expressar melhor, a planejar minhas ações, a traçar metas e alcança-las, aprendi a ser crítica, deixando de ser "vaquinha de presépio", expondo minha opinião e descontentamento (Qacs).

A maior parte dos ACSs considerou que o curso técnico não era valorizado pela sua equipe, mas acreditavam que, com o desenvolvimento de um trabalho mais qualificado com base nos conhecimentos adquiridos no curso, acabariam tendo esse reconhecimento. Alguns ACSs observaram mudanças positivas na sua integração com a equipe. Consideraram que as repercussões do curso na própria vida foram positivas e apontaram como exemplo o maior ânimo para a vida e para as lutas pelos seus ideais, melhora na autoestima, diminuição de preconceitos e respeito às diferenças, e maior união entre a categoria profissional.

No meu caso, foi muito legal: eu tomei coragem, participei de um congresso no Hospital Pedro Ernesto, apresentei um trabalho meu... Eu consegui ter outra visão do meu trabalho, quando você está dentro do foco você não consegue ter muita visão do que você esta fazendo (ACS). 
Hoje consigo perceber que podemos sempre estar nos superando e nos surpreendendo (Qacs).

O crescimento alcançado foi também atribuído à metodologia desenvolvida no curso técnico:

Tudo que se fala vocês respeitam, eu venho aprendendo isso até para escutar melhor o paciente ou cliente para quem a gente faz acompanhamento (ACS).

Os ACSs questionaram a efetividade das mudanças que deveriam acontecer com a implantação da ESF e comentaram as dificuldades em colocar em prática as aprendizagens obtidas no curso técnico.

Na prática, muita coisa que eu aprendi lá, quando eu chegava na unidade de saúde, não podia fazer (ACS).

Médico entra, médico sai. O vínculo mesmo é com ACS; com o médico e a enfermeira não se tem vínculo, porque é uma rotatividade muito grande (ACS).

Em relação aos conhecimentos que gostariam de aprofundar, os ACSs mencionaram o desejo de conhecer mais sobre as doenças, justificando esse desejo pelo fato de facilitar a detecção de casos que precisam de acompanhamento. Foi sugerido, ainda, que a equipe fizesse o curso junto com os agentes, a fim de tentarem, juntos, mudar o modelo de atenção.

No que se refere à formação do agente comunitário, enfermeiros e médicos ressaltam que todos os demais membros da equipe têm uma formação profissional, enquanto o ACS é o único que é contratado sem formação específica. Existem alguns pontos positivos percebidos pelos profissionais de nível superior em relação à formação técnica realizada pelos ACS.

Uma colaboração que eu vejo que foi muito marcante nessa formação técnica é principalmente no aspecto da vigilância epidemiológica, a contribuição na visão de território, quando eles vêm colaborar para a nossa competência enquanto Estratégia Saúde da Família. A questão de ter uma visão diferenciada enquanto profissional de saúde e não meramente como pessoas que foram selecionadas dentro da comunidade para atuarem como profissionais (E1).

Olha, teve uma das agentes que depois de começar a fazer o curso técnico mudou muito [...] no sentido de questionar, de trazer demandas, de levantar questões que eu mesmo não via, de realmente fazer o papel do agente comunitário, e a gente ficou muito feliz com isso (M2). 
No entanto, a maior parte dos médicos e enfermeiros entrevistados mencionaram não ter sentido nenhuma diferença, o que atribuíram ao fato de alguns ACSs não quererem mudanças. Também foi considerado negativo o fato de não ter havido uma seleção para a inscrição dos ACSs no curso, uma vez que todos aqueles que ainda não haviam feito o curso foram inscritos. Essa percepção dos profissionais de nível superior contrasta com a percepção dos próprios ACSs abordada anteriormente.

Em relação aos conhecimentos que precisam ser reforçados, as sugestões foram relacionadas a doenças, preenchimento de fichas, português e oratória, e trabalho em equipe. Várias das sugestões dadas pelos profissionais de nível superior já fazem parte do currículo do Ctacs.

Entre as dificuldades no processo de trabalho mencionadas pelos ACSs, está a falta de compreensão da sua função por parte de membros da equipe e a organização do serviço que prioriza tarefas burocráticas em detrimento do acompanhamento da população ou das atividades educativas. Com frequência, os ACSs mencionaram a equipe técnica sem se sentir parte dessa equipe.

É muito fácil você chegar para mim e falar: "Você tem que cadastrar todos os domicílios". Mas, só que eu que estou naquela microárea sei que, naquele domicílio, eu não posso cadastrar e muito menos pedir documentação... (ACS).

Também os profissionais de nível superior sentem que as necessidades locais não são tomadas em consideração quando a Prefeitura estabelece a rotina de trabalho, como, por exemplo, os turnos de consulta, visita e promoção da saúde.

Ainda que todos considerassem o papel do ACS essencial para o desenvolvimento do trabalho da equipe, foi exteriorizado um descontentamento e uma tensão entre a maioria dos profissionais de nível superior e os agentes de saúde.

Eles precisam fazer a parte deles para serem reconhecidos. Os próprios agentes não fazem por onde, não se valorizam (E2).

Referindo-se a uma ACS antiga: não a vejo apostando no papel dela de agente comunitário - desmotivada, cansada, ausente. Saber ela sabe fazer, mas... (M4).

Alguns médicos e enfermeiros expressaram também sua preocupação em relação à preservação do sigilo profissional por parte dos ACSs, colocando em dúvida se a informação não circularia pela comunidade.

O tema das mudanças efetivas produzidas pela implantação da ESF é abordado por diferentes autores, como Merhy e Franco (2002), que ques- 
tionam o 'discurso mudancista' atribuído ao Programa Saúde da Família; Favoreto e Camargo Jr. (2002), que apontam problemas como a resolutividade dos serviços de saúde da família, entre os quais o sistema de referência e contrarreferência; e, ainda, Silva e Dalmaso (2002), Tomaz (2002) e Nogueira (2002), que discutem as atribuições dos agentes comunitários e a distorção de seu papel na ESF. Ainda que esse discurso não seja objeto da pesquisa em questão, cabe ressaltar que todos os profissionais de nível superior questionaram a efetividade dessas mudanças, o que indica a necessidade de aprofundamento do tema. Os motivos alegados variaram, sendo atribuídos à violência, que além de dificultar o acesso dos profissionais à área, também influencia a vida da população; à organização do serviço, que dificulta a saída dos médicos e enfermeiros da unidade de saúde para a realização de visitas domiciliares; e à própria compreensão da população, que ainda busca o serviço principalmente em função da doença.

Um dos agentes de saúde fez uma análise crítica sobre o modelo que está sendo implantado atualmente no município do Rio de Janeiro e explica o afastamento desse modelo da proposta inicial de territorialização da ESF.

O modelo anterior desse trabalho seria de levar a saúde para dentro da comunidade para aquelas pessoas que não têm muito acesso aos médicos lá fora. Porque nem todo mundo que mora dentro de comunidade tem como se locomover até um local um pouco mais distante, e essa parceria com a comunidade fazia que a comunidade se sentisse mais coberta em relação à saúde. O modelo de hoje está tirando praticamente de dentro das comunidades esse PSF e trazendo para o asfalto. Apesar de o agente comunitário continuar visitando a residência, o usuário está se sentindo como se tivessem dado um pedaço do doce a ele e tirado o restante. A prefeitura, com o modelo Clínica da Família, que tem de ser num local próprio, grande, onde se possa ter um conforto melhor, dificultou para as comunidades que não têm esse espaço dentro delas (ACS).

As frequentes queixas mútuas entre a maioria dos ACSs que participaram dos grupos focais e os profissionais de nível superior entrevistados indicam uma necessidade de buscar entender melhor seus motivos e trabalhar especificamente a questão do relacionamento da equipe.

\section{Considerações finais}

Em relação à indagação inicial que serve de base para a análise das mudanças percebidas em decorrência da formação profissional, cabe ressaltar que grande parte dos relatos colhidos questionam as conquistas na mudança de modelo de atenção pretendida pela implantação da Estratégia 
Saúde da Família. Ainda que as explicações variem, elas têm em comum a ênfase do processo de trabalho sobre a doença, sua burocratização, as dificuldades de referência e contrarreferência, a cobrança de metas que toma como parâmetro de avaliação a quantidade sem considerar a qualidade do trabalho desenvolvido e o estabelecimento de atividades que não levam em conta a realidade local.

A demanda da população, e mesmo da equipe de saúde, em relação ao trabalho do ACS gira quase sempre em torno da resolução de problemas de saúde já instalados, exigindo intervenção médica, exames e medicamentos. As práticas educativas acabam ficando frequentemente em segundo plano, e a mediação educativa assume a forma de prescrição relacionada aos problemas de saúde instalados. Ao mesmo tempo, um agir educativo que se liberta dessa carga prescritiva pode ser observado nas relações informais dos ACSs, nas quais são colocados saberes relevantes não sistematizados a serviço da resolução de problemas. Essas vivências de relações e diálogos cotidianos não são reconhecidas na sua amplitude e potencialidade, e sequer são registradas de alguma forma. A sistematização mensal do Sistema de Informação da Atenção Básica (Siab) representa apenas uma pálida e inexpressiva ideia do que efetivamente esse ACS fez e produziu de ações e saberes no seu cotidiano.

Na percepção dos médicos e enfermeiros entrevistados, a importância do ACS se sustenta em sua atuação como facilitador dos trabalhos realizados pela equipe, como aquele que entende melhor a realidade da população, que aponta os riscos encontrados no território e cria o vínculo com os moradores. As características mencionadas confirmam o potencial desse novo trabalhador na equipe de saúde como facilitador do processo de mudança do modelo de atenção. Parte delas está relacionada à própria origem do ACS, que é um morador da área onde atua, e, portanto, não implica uma formação profissional; porém, por sua vez, reconheceu-se o fato de o curso ter facilitado uma abordagem mais integral da situação de saúde e a identificação de riscos para a saúde.

O novo modelo de atenção implantado recentemente no município do Rio de Janeiro é questionado pelo fato de as Clínicas da Família estarem localizadas, em sua grande maioria, em áreas externas às comunidades, em contradição com a proposta inicial de aproximar o serviço de saúde do território de moradia da população. Como consequência, é mencionada uma maior dificuldade de acesso dos moradores e o distanciamento dos profissionais da realidade vivenciada pela população.

A falta de uma formação técnica para o ACS é sinalizada por enfermeiros e médicos como uma diferença entre esse componente da equipe de saúde e seus demais integrantes. Essa falta de formação profissional seguramente é também um dos motivos para que os ACSs se refiram à equipe técnica, sem se sentirem parte da mesma. 
Além da falta de formação profissional, existem outros fatores que tensionam a relação entre os ACSs e os demais membros da equipe. Apesar desse não ter sido um tema investigado, o conflito esteve presente na fala da maioria dos participantes da pesquisa, o que indica uma necessidade na busca de novos conhecimentos.

Quanto à contribuição da formação técnica para a atuação dos ACSs, existe uma contradição clara entre o ponto de vista dos médicos e enfermeiros e a percepção dos próprios ACSs. Enquanto médicos e enfermeiros perceberam poucas mudanças ocorridas em decorrência do curso técnico frequentado pelos ACSs, os agentes de saúde foram unânimes em apontar mudanças tanto em relação ao trabalho quanto em relação à sua própria vida. Referem-se à compreensão de um modelo de atenção mais humanizado, integral, com trabalho intersetorial; destacam conhecimentos adquiridos em relação a políticas de saúde, ao planejamento, à informação e à educação em saúde; e consideram que as mudanças também se refletiram nas suas relações com a equipe.

A maioria dos ACSs considerou que o curso não era valorizado por sua equipe de saúde, o que, de certa forma, é coerente com a perspectiva dos médicos e enfermeiros em não ter observado mudanças.

Ainda que os membros da diretoria do Sindacs-RJ não estivessem frequentando o curso, eles reconheceram a importância da realização do curso técnico para a formação profissional dos ACSs, e a extensão do curso aos demais profissionais é uma das principais pautas de luta do Sindacs-RJ. Por ser o ACS um componente da equipe contratado sem nenhuma formação profissional específica no campo da saúde, foi justificada a necessidade do curso introdutório, sem, no entanto, anular a necessidade do curso técnico. A importância do curso técnico foi fundamentada pela complexidade do trabalho realizado pelos ACSs.

As percepções contraditórias dos componentes das equipes em relação à influência do curso técnico na atuação dos ACSs indicam a necessidade de aprofundamento de seus motivos. Uma das questões poderia ser a não existência de condições nas equipes para o diálogo entre saber popular e saber científico e entre experiências de vida tão diferentes. Por outra parte, os próprios ACSs reconhecem a dificuldade de colocar em prática os conhe-cimentos adquiridos no curso. Quais os fatores que impedem ou dificultam aos ACSs desenvolverem os potenciais adquiridos no curso? Será que com o desenvolvimento de suas práticas futuras os resultados poderão ser mais bem observados?

Enquanto se produzem as respostas a essas e outras questões, pode-se concluir pela reafirmação de que a formação técnica dos ACSs, como direito ao trabalho digno e à formação de qualidade, representa um avanço para a qualificação do trabalho em saúde no SUS e para o cumprimento dos princípios que o sustentam como política universal. 
Resumen Este artículo presenta los resultados de la investigación realizada entre 2008 y 2011 en el ámbito de la Escuela Politécnica de Salud Joaquim Venâncio, cuyo objeto fue la formación técnica del agente comunitario de salud (ACS). El eje central del análisis fueron los cambios que se producen en el proceso de trabajo derivados de la reorientación del modelo de atención a la salud pretendida con la implantación de la Estrategia Salud Familiar. En la encuesta participaron 32 ACS, alumnos del curso, ocho profesionales de sus equipos y dos ACS de la dirección del Sindicato de Agentes Comunitarios de Salud de Río de Janeiro que no eran alumnos del curso. En forma general, los entrevistados cuestionaron las conquistas pretendidas con el cambio en el modelo de atención. En cuanto a la contribución de la formación técnica para la actuación de los ACS, existe una contradicción clara entre la percepción de éstos y la perspectiva de médicos y enfermeros. Mientras estos últimos observaron pocos cambios ocurridos en la actuación de los ACS como resultado del curso realizado, los agentes fueron unánimes en indicar cambios con relación al trabajo y a su propia vida. La tensión en la relación entre los ACS y los demás profesionales del equipo fue constatada en los resultados de la investigación y señala una necesidad de profundizar esta relación.

Palabras clave Formación profesional; agente comunitario de salud; salud de la familia.

\section{Notas}

1 Escola Politécnica de Saúde Joaquim Venâncio, Fundação Oswaldo Cruz, Rio de Janeiro, RJ, Brasil.

Doutora em Saúde Pública pela Escola Nacional de Saúde Pública Sergio Arouca (Ensp/Fiocruz). <vejoana@fiocruz.br>

Correspondência: Escola Politécnica de Saúde Joaquim Venâncio/Fiocruz, Av. Brasil, 4.365, sala 311, Manguinhos, Rio de Janeiro, RJ, Brasil, CEP 21040-360.

2 Universidade do Estado do Rio de Janeiro, Rio de Janeiro, RJ, Brasil

Doutora em Saúde Pública pela Escola Nacional de Saúde Pública Sergio Arouca (Ensp/Fiocruz). <helena.david@uol.com.br>

3 Ficou conhecida como Lei de Responsabilidade Fiscal a lei complementar n. 101, de 4 de maio de 2000, a qual, dentre outras coisas, determina que a despesa total com pessoal não poderá ser maior do que $50 \%$ da receita corrente líquida da União e do que $60 \%$ da receita corrente líquida dos estados e municípios, a cada ano. 


\section{Referências}

BORNSTEIN, Vera J.; STOTZ, Eduardo N. O trabalho dos agentes comunitários de saúde: entre a mediação convencedora e a transformadora. Trabalho, Educação e Saúde, Rio de Janeiro, v. 6, n. 3, p. 457-480, nov. 2008/fev. 2009.

BRASIL. Ministério da Saúde. Ministério da Educação. Referencial curricular para curso técnico de agentes comunitários de saúde: área profissional saúde. Brasília: Ministério da Saúde, 2004.

Ministério da Saúde. Departamento de Atenção Básica. Política nacional de atenção básica. Brasília: Ministério da Saúde, 2006.

Ministério da Saúde. Departamento de Atenção Básica. Portal da Atenção Básica. Situação de Implantação de Equipes de Saúde da Família, Saúde Bucal e Agentes Comunitários de Saúde, Brasil, agosto 2011 Brasília: Departamento de Atenção Básica, 2011. Disponível em: <http://dab.saude.gov. br/abnumeros.php\#mapas>. Acesso em: 23 fev. 2012 .

FAVORETO, Cesar Augusto O.; CAMARGO JR., Kenneth Rochel de. Alguns desafios conceituais e técnico-operacionais para o desenvolvimento do Programa de Saúde da Família como uma proposta transformadora do modelo assistencial. Physis: Revista de Saúde Coletiva, Rio de Janeiro, v. 12, n.1, p. 59-75, 2002.

FREIRE, Paulo. A pedagogia do oprimido. 17. ed. Rio de Janeiro: Paz e Terra, 1987.

MATTOS, Ruben A. Os sentidos da integralidade: algumas reflexões acerca de valores que merecem ser defendidos. In: PINHEIRO, Roseni; MATTOS, Ruben A. Os sentidos da integralidade na atenção e no cuidado à saúde. Rio de Janeiro: Uerj/IMS/Abrasco, 2001. p. 39-64.

MERHY, Emerson E.; FRANCO, Túlio B. Programa Saúde da Família: somos contra ou a favor?. Saúde em debate, Rio de Janeiro, v. 26, n. 60, p.118-122, 2002.
Por uma composição técnica do trabalho em saúde centrada no campo relacional e nas tecnologias leves. Apontando mudanças para os modelos tecno-assistenciais. Saúde em debate, Rio de Janeiro, v. 27, n. 65, p. 316-323, 2003.

MINAYO, Maria Cecília de S. O desafio do conhecimento: pesquisa qualitativa em saúde. 6. ed. São Paulo; Rio de Janeiro: Hucitec; Abrasco, 1999.

MOROSINI, Márcia V.; CORBO, Ana-Maria D'Andrea; GUIMARÃES, Cátia C. O agente comunitário de saúde no âmbito das políticas voltadas para a atenção básica: concepções do trabalho e da formação profissional. Trabalho, Educação e Saúde, Rio de Janeiro, v. 5, n. 2, p. 261-280, 2007.

NOGUEIRA, Roberto P. O trabalho do agente comunitário de saúde: entre a dimensão técnica 'universalista' e a dimensão social 'comunitarista'. Interface: Comunicação, Saúde, Educação, Botucatu, v. 6, n. 10, p. 91-93, 2002

PEREIRA, Isabel B.; RAMOS, Marise N. Educação Profissional em Saúde. Rio de Janeiro: Editora Fiocruz; 2006.

SILVA Joana A.; DALMASO Ana Silvia W. O agente comunitário de saúde e suas atribuições: os desafios para os processos de formação de recursos humanos em saúde. Interface: Comunicação, Saúde, Educação, Botucatu, v. 6, n.10, p. 75-83, 2002.

SOUZA, Heloiza M. de. Saúde da Família: desafios e conquistas. In: NEGRI, Barjas; VIANA, Ana Luiza d'Ávila. (Orgs.). O Sistema Único de Saúde em dez anos de desafio. São Paulo: Sociedade Brasileira de Vigilância de Medicamentos, Centro de Estudos Augusto Leopoldo Ayrosa Galvão, 2002. p. 221-240.

SPINK, Mary J.; MENEGON, Vera M. A pesquisa como prática discursiva: superando os 
horrores metodológicos. In: SPINK, Mary Jane (Org.). Práticas discursivas e produção de sentidos no cotidiano: aproximações teóricas e metodológicas. São Paulo: Cortez; 2000. p. 63-92.

TEIXEIRA, Carmen F. A mudança do modelo de atenção à saúde no SUS: desatando nós, criando laços. In: TEIXEIRA, Carmen F.; SOLLA, Jorge P. Modelo de atenção à saúde: promoção, vigilância e saúde da família. Salvador: EDUFBA, 2006. p. 19-58.
TOMAZ João B. C. O agente comunitário de saúde não deve ser um 'super-herói'. Interface: Comunicação, Saúde, Educação, Botucatu, v. 6, n. 10, p. 84-87, 2002.

VASCONCELOS, Eymard M. Educação popular e a atenção à saúde da família. São Paulo: Hucitec, 1999.

Recebido em 24/04/2012

Aprovado em 20/02/2013 